\title{
Boston Naming Test: Gender Differences in Older Adults with and without Alzheimer's Dementia
}

\author{
James R. Hall ${ }^{1,2}$, Hoa T. Vo ${ }^{2}$, Leigh A. Johnson ${ }^{3}$, April Wiechmann ${ }^{1}$, Sid E. O’Bryant ${ }^{1,3}$ \\ ${ }^{1}$ Institute of Aging and Alzheimer's Disease Research, \\ University of North Texas Health Sciences Center, Fort Worth, USA \\ ${ }^{2}$ Department of Psychiatry, Behavioral Health and Neuroscience, \\ University of North Texas Health Sciences Center, Fort Worth, USA \\ ${ }^{3}$ Department of Internal Medicine, University of North Texas Health Sciences Center, \\ Fort Worth, USA \\ Email: \{james.hall, hoa.vo, leigh.johnson, April.Wiechmann, sid.obryant\}@unthsc.edu
}

Received April 5 ${ }^{\text {th }}$, 2012; revised April 30 ${ }^{\text {th }}, 2012$; accepted May 28 $8^{\text {th }}, 2012$

\begin{abstract}
The study clarifies the relationship between gender and performance on the BNT by controlling for the effects of demographic and health risk factors. Participants were 468 outpatient individuals (153 diagnosed with probable Alzheimer's Disease (AD) and 318 cognitively intact) enrolled in the Texas Alzheimer's Research and Care Consortium cohort. Participants under went evaluations including medical examination, interview, neuropsychological testing, and blood draw. The neuropsychological assessment consisted of the Wechsler Digit Span, Logical Memory, and Visual Reproduction, along with the Trail Making Test, Boston Naming Test (60-item version), verbal fluency (FAS), and the Geriatric Depression Scale (GDS-30). To control for severity of cognitive impairment only mild AD as shown by a CDR global score of 0.5 or 1.0 were used. Control males outperformed females $(\mathrm{F}=10.81, p<.000$, ES $=.20)$. $\mathrm{AD}$ males also performed significantly better than $\mathrm{AD}$ females $(\mathrm{F}=17.13, p<.000$, $\mathrm{ES}=.25)$. Gender differences remain after covarying for estimated IQ, age, education, and presence of hyperlipidemia and hypertension. Overall, within-group and between-group comparisons support prior findings that males perform significantly better compared to females on the BNT even after controlling for health and level of decline. Findings have implications for clinical practice and prospective test norm considerations.
\end{abstract}

Keywords: Boston Naming; Alzheimer’s Disease; Cardiovascular Risks; Gender

\section{Introduction}

Naming has long been recognized as one of the most sensitive aspects of underlying aphasic disturbances. The Boston Naming Test (BNT; Kaplan, Goodglass, \&Weintraub, 1983) has been used predominantly in older adults to assess the degree of language disturbances. Studies have demonstrated that the BNT (a measure of confrontational naming) is useful for detecting progressive aphasia (Rogalski, Rademaker, \& Weintraub, 2007) and can also serve as a clinical tool for differential diagnosis of dementia (Randolph, Lansing, Ivnik et al., 1999; Tsolaki, Tsantali, Lekka et al., 2003). Impaired performance on the BNT has been implicated in Alzheimer's disease (AD), an amnestic dementia that impairs linguistic abilities leading to eventual complete loss of language (Taler \& Phillips, 2008).

The majority of the research on the BNT and dementia has examined the effects of a number of variables including intellectual capacity or intelligence quotient (IQ) (VanGorp, Satz, Kiersch, \& Henry, 1986), age (Albert, Heller, \& Milberg, 1988; Morrison, Ellis, \& Quinlan, 1992), education (Welch, Doineau, Johnson, \& King, 1996; Zec, Burkett, Markwell, \& Larsen, 2007), and ethnicity (Roberts \& Hamsher, 1984; Ross \& Lichtenberg, 1997). Welch and colleagues (1996), found that naming ability is slightly decreases with age after controlling for education, with high school graduates demonstrating more robust abilities. To date, only a few studies have examined gender differences in combination with age, education and level of cognitive impairment (Zec et al., 2007; Randolph et al., 1999; Ripich, Petrill, Withhouse, \& Ziol, 1995). The study by Randolph et al. (1999) is the only research we are aware of that examined gender differences in BNT performance in both cognitively intact individuals and demented patients. The methodology used to determine level of decline or the severity of impairment for the AD patient was not clearly delineated in the Randolph et al. study.

In order to clarify the role of gender differences on BNT performance it is important to take into account specific health risk factors that may affect the cognitive processes involved in object naming. To our knowledge, the potentially confounding effects of vascular health have not been controlled for in any of the research on BNT performance and gender. Vascular functioning has been shown to have a significant impact on cognitive processes related to naming. Processing speed and impaired executive functioning has been associated with cognitive declines in diseases with vascular etiologies (Prins, Dijk, Heijer et al., 2005). Although the BNT is not a timed sensitive measure and therefore not directly impacted by processing speed, proficient performance on the task requires sufficient encoding and processing of a visual stimulus (Grossman, McMillan, Moore et al., 2004) within a relatively limited time frame (typically 20 seconds Diseases due to vascular impairment lead to subcortical and white-matter changes (Levy \& Chelune, 2007), which contribute to the deterioration of visual perceptual processes and hence may impair the ability to recognize and 
process the visual stimuli effectively. Additionally, gender differences have been noted in the literature suggesting that men are at increased vascular risk compared to women (BarrettConnor \& Bush, 1991; White, Rivera, \& Davison, 2000). The present study attempts to clarify the relationship between gender and performance on the BNT by controlling for the effects of education, age, and most importantly, vascular risks in cognitively impaired and cognitively intact elderly.

\section{Method}

468 individuals (153 diagnosed with probable AD and 318 determined to be cognitively intact) enrolled in the Longitudinal Research Cohort of the Texas Alzheimer's Research and Care Consortium (TARCC), a well characterized cohort of AD and normal controls assessed annually were analyzed. The methodology of the TARCC project has been described in detail elsewhere (Waring, O’Bryant, Reich et al., 2008). Briefly, each participant undergoes an annual evaluation that includes a medical examination, interview, neuropsychological testing, and blood draw. AD patients met consensus based diagnosis for probable AD based on NINCDS-ADRDA criteria (McKhann, Drachman, Folstein et al., 1984). To control for the confounding effect of severity of impairment and stage of disease the AD sample was limited to individuals with mild AD as shown by a CDR global score of .5 or 1.0.

The final AD sample consisted of 82 males and 71 females. Controls (110 males; 208 females) performed within normal limits on psychometric assessment and received a CDR global score of .0. The breakdown of the CDR global scores was as follows: $0=318$ (controls), $.5=61$, (AD), $1.0=92$ (AD). Participants in the probable AD group were 54 to 102 years of age (Males $M=75.17$, $\mathrm{SD}=7.95$; Females $M=76.81$, $\mathrm{SD}=8.09$ ) and from 52 to 93 (Males $M=72.78$, SD $=8.47$; Females $M=$ $69.98, \mathrm{SD}=8.70$ ) for the control group. The characteristics of the participants are presented in Table 1. Majority of participants were Caucasian (93\%), black or African American was the next largest group accounting for $4 \%$ of the sample. The TARCC project received Institutional Review Board approval and all participants and/or caregivers signed written informed consent documents.

The neuropsychological assessment battery used in the TARCC core battery consists of the following instruments: Wechsler digit span, Logical Memory, and Visual Reproduction, along with the Trail Making Test, Boston Naming Test (60item version), the FAS measure of verbal fluency, the Geriatric Depression Scale (GDS-30), the AMNART to estimate verbal

Table 1.

Demographic characteristics of the sample.

\begin{tabular}{cccccc}
\hline & \multicolumn{2}{c}{ AD $(\mathrm{N}=153)$} & \multicolumn{2}{c}{ NC $(\mathrm{N}=318)$} & $p$ \\
\hline Gender (M, F) & 82 & 71 & 110 & 208 & .000 \\
Age (M, SD) & 75.173 & 76.81 & 72.78 & 69.98 & \\
& $(7.95)$ & $(8.09)$ & $(8.47)$ & $(8.70)$ & .001 \\
Education & 15.27 & 14.20 & 16.24 & 15.29 & .212 \\
& $(3.04)$ & $(6.33)$ & $(2.75)$ & $(6.12)$ & \\
Estimated IQ & 109.12 & 109.13 & 117.44 & 115.34 & .000 \\
& $(12.12)$ & $(12.90)$ & $(8.99)$ & $(10.47)$ & \\
\hline
\end{tabular}

$\mathrm{M}=$ Male, $\mathrm{F}=$ Female, $\mathrm{M}=$ Mean, $\mathrm{SD}=$ Standard Deviation, $\mathrm{IQ}=$ Intelligence Quotient.
IQ and the Clinical Rating scale (CDR). The cognitive evaluation was administered under controlled testing setting according to standardized instructions.

\section{Results}

ANCOVA was applied to assess within group gender differences. Comparisons were made within group to assess for gender differences using ANCOVAs. The BNT scale scores were used in all analyses. Covariates included age, estimated IQ, level of formal education, existing hypertension and hyperlipidemia, and number of years smoked. As expected, in the control group, males outperformed females $(\mathrm{F}=10.81, p<.000$, $\mathrm{ES}=.20)$ with means $(\mathrm{M}=13.46$; $\mathrm{SD}=2.89)$ for males and $(\mathrm{M}$ $=11.76 ; \mathrm{SD}=3.10)$ for females. Males performed significantly better than females in the AD group $(\mathrm{F}=17.13, p<.000$, ES $=.25)$ with means of $(\mathrm{M}=8.43$; $\mathrm{SD}=3.82)$ for males and $(\mathrm{M}=$ 8.20; $\mathrm{SD}=3.16$ ) for females. Overall, within-group and between-group comparisons support prior findings that males perform significantly better compared to females on the BNT ( $\mathrm{F}=68.06, p<.000)$ even after covarying for level of estimated IQ $(\mathrm{F}=54.24, p<.000)$, age, $(\mathrm{F}=11.27, p<.001)$, education $(\mathrm{F}=1.56, p=.212)$, and the presence of hyperlipidemia ( $\mathrm{F}$ $=.18, p=.67)$ and hypertension $(\mathrm{F}=.22, p=.640)$. After controlling for level of decline (using CDR scores) and covariates, gender differences remain significant $(F=11.30, p<.000$; ES $=.19)$ with robust naming abilities among $\mathrm{AD}$ males $(\mathrm{M}=7.63$; $\mathrm{SD}=3.65)$ compared to females $(\mathrm{M}=6.60 ; \mathrm{SD}=3.45)$. Effect size for gender difference in both normal controls and probable $\mathrm{AD}$ groups was above 0.49 . Overall, performance was best among control males and worst among females with probable $\mathrm{AD}$ (see Figure 1).

\section{Discussion}

The current finding provides support for gender differences in performance on the Boston Naming Test for both cognitively impaired and intact elderly. Prior studies have implicated the role of age, education, and minority status, suggesting interactions between these variables (Connor, Spiro, Obler, \& Albert, 2004; Zec et al., 2007). Similar to previous findings (Randolph et al., 1999), males generally out-performed females in both control and AD groups. The present study, after controlling all previously indicated relevant factors in addition to cardiovascular health variables, found a consistent and nontrivial effect

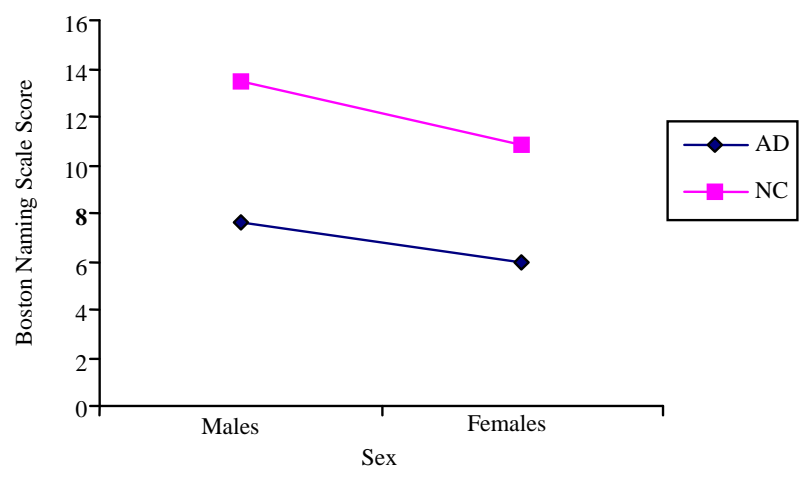

$\mathrm{AD}=$ Alzheimer's, $\mathrm{NC}=$ Normal Controls

Figure 1.

Sex differences in group means. 
suggesting that both the control and the diagnostic group with males scoring higher than females. Due to the relatively small body of literature that have examined the current topic, it remains unclear why males perform better than females on the BTN. It can be speculated that, first and most simply, males start a higher baseline as observed in cognitively intact individuals in the present sample. The present study did not demonstrate educational differences as reported in several other studies (Albert et al., 1988; Fastenau, Denburg, \& Mauer, 1998; LaBarge, Edwards, \& Knesevich, 1986; Nicholas, Obler, Albert, \& Goodglass, 1985). Other studies have suggested that education is an important variable (Borod, Goodglass, \& Kaplan, 1980; Hawkins, Sledge, Orleans et al., 1993; Henderson, Frank, \& Pigatt et al., 1998; Kent \& Luszcz, 2002; Welch et al., 1996; Zec et al., 2007). Despite not finding significant effects of education, our study was consistent with previous studies (Albert et al., 1988; Henderson et al., 1998; VanGorp et al., 1986) supporting the role of IQ in BNT performance. The absence of a significant education effect in our study may be due to the restricted range of education in both controls and $\mathrm{AD}$ groups.

The effects of the presence hypertension and hyperlipidemia were not significantly associated with performance on BNT. It has been hypothesized that confrontational naming may be impacted by subcortical white-matter changes effected by vascular risks producing inefficient processing of visual stimuli (Prins et al., 2005). The current findings suggest that co-morbid vascular risks generally do not impact performance on the BNT. However, additional research is warranted in this area because it remains unclear whether gender differences will be detected in patients with dementia of vascular etiologies at various stages of decline.

There are a number of limitations that may effect generalizebility of the findings including sample size and the cross-sectional nature of the study. The sample was also relatively highly educated and predominately urban and Caucasian. Despite these limitations, the overall findings demonstrate the importance of accounting for gender differences and advocates for the use of gender as a factor when evaluating performance on the BNT. Among the factors that impact performance, including IQ, level of formal education, age, vascular health status and cognitive status, the present data suggests that gender is the most robust variable associated with performance on the BNT. Prospective and longitudinal designs may contribute to understand of progression and changes in confrontation naming capacity among elderly men and women.

\section{Acknowledgements}

This study was made possible by the Texas Alzheimer's Research Consortium (TARC) funded by the state of Texas through the Texas Council on Alzheimer's Disease and Related Disorders.

\section{REFERENCES}

Albert, M. S., Heller, H. S., \& Milberg, W. (1988). Changes in naming ability with age. Psychology and Aging, 3, 173-178. doi:10.1037/0882-7974.3.2.173

Barrett-Connor, E., \& Bush, T. L. (1991). Estrogen and coronary heart disease in women. Journal of the American Medical Association, 265, 1861-1867. doi:10.1001/jama.1991.03460140089033

Borod, J. C., Goodglass, H., \& Kaplan, E. (1980). Normative data on the Boston Diagnostic Aphasia Examination, parietal lobe battery, and the Boston Naming Test. Journal of Clinical Neuropsychology, 2, 209-215. doi:10.1080/01688638008403793

Connor, L. T., Spiro III, A., Obler, L. K., \& Albert, M. L. (2004). Change in object naming ability during adulthood. Journals of Gerontology, Series B: Psychological Sciences and Social Sciences, 59, P203P209. doi:10.1093/geronb/59.5.P203

Fastenau, P. S., Denburg, N. L., \& Mauer, B. A. (1998). Parallel short forms of the Boston Naming Test: Psychometric properties and norms for older adults. Journal of Clinical and Experimental Neuropsychology, 20, 828-834. doi:10.1076/jcen.20.6.828.1105

Grossman, M., McMillan, C., Moore, P., Ding, L., Glosser, G., \& Work, M. (2004). What's in a name: Voxel-based morphometric analysis of MRI and naming difficulty in Alzheimer's disease, frontotemporal dementia and corticobasal degeneration. Brain, 127, 628-649. doi:10.1093/brain/awh075

Hawkins, K. A., Sledge, W. H., Orleans, J. E., Quinlan, D. M, Rakfeldt, J., \& Huffman, R. E. (1993). Normative implications of the relationship between reading vocabulary and Boston Naming Test performance. Archives of Clinical Neuropsychology, 8, 525-537.

Henderson, L. W., Frank, E., Pigatt, T., Abramson, R. K., \& Houston, M. (1998). Race, gender, and educational level effects on Boston Naming Test scores. Aphasiology, 12, 901-911. doi:10.1080/02687039808249458

Kaplan, E., Goodglass, H., \& Weintraub, S. (1976). Boston naming test. Boston: Boston University.

Kent, P. S., \& Luszcz, M. A. (2002). A review of the Boston Naming Test and multiple-occasion normative data for older adults on 15item versions. Clinical Neuropsychologist, 16, 555-574. doi:10.1076/clin.16.4.555.13916

LaBarge, E., Edwards, D., \& Knesevich, J. W. (1986). Performance of normal elderly on the Boston Naming Test. Brain and Language, 27, 380-384. doi:10.1016/0093-934X(86)90026-X

Levy, J. A., \& Chelune, G. J. (2007). Cognitive-behavioral profiles of neurodegenerative dementias: Beyond Alzheimer's disease. Journal of Geriatric Psychiatry and Neurology, 20, 227-238. doi:10.1177/0891988707308806

McKhann, G., Drachman, D., Folstein, M., Katzman, R., Price, D., \& Stadlan, E. M. (1984). Clinical diagnosis of Alzheimer's disease: Report of the NINCDS-ADRDA Work Group under the auspices of the Department of Health and Human Services Task Force on Alzheimer's Disease. Neurology, 34, 939-944. doi:10.1212/WNL.34.7.939

Morrison, C. M., Ellis, A. W., \& Quinlan, P. T. (1992). Age of acquisition, not word frequency, affects object naming, not object recognition. Memory and Cognition, 20, 705-714. doi:10.3758/BF03202720

Nicholas, M., Obler, L., Albert, M. L., \& Goodglass, H. (1985). Lexical retrieval in healthy aging. Cortex, 21, 595-606.

Prins, D. N., Dijk, E. J., Heijer, T., Vermeer, S. E. et al. (2005). Cerebral small-vessel disease and decline in information processing speed, executive function and memory. Brain, 128, 2034-2041. doi:10.1093/brain/awh553

Randolph, C., Lansing, A. E., Ivnik, J. R., Cullum, C. M., \& Hermann, B. P. (1999). Determinants of confrontation naming performance. Archives of Clinical Neuropsychology, 14, 489-496.

Ripich, D. N., Petrill, S. A., Whitehouse, P. J., \& Ziol, E. W. (1995). Gender differences in language of Alzheimer's disease patients: A longitudinal study. Neurology, 45, 299-302. doi:10.1212/WNL.45.2.299

Roberts, R. J., \& Hamsher, K. (1984). Effects of minority status on facial recognition and naming performance. Journal of Clinical Psychology, 40, 539-545.

doi:10.1002/1097-4679(198403)40:2<539::AID-JCLP2270400226> 3.0.CO;2-8

Rogalski, E., Rademaker, A., \& Weintraub, S. (2007). Primary progressive aphasia: Relationship between gender and severity of language impairment. Cognitive and Behavioral Neurology, 20, 38-43. doi:10.1097/WNN.0b013e31802e3bae

Ross, T. P., \& Lichtenberg, P. A. (1997). Expanded normative data for the Boston Naming Test in an urban medical sample of elderly adults. 
Journal of the International Neuropsychological Society, 3, 70.

Taler, V., \& Phillips, N. A. (2007). Language performance in Alzheimer's disease and mild cognitive impairment: A comparative review. Journal of Clinical and Experimental Neuropsychology, 30, 551-556.

Tsolaki, M., Tsantali, E., Lekka, Kiosseoglou, G., \& Kazis, A. (2003). Can the Boston Naming Test be used as a clinical tool for differential diagnosis in dementia? Brain and Language, 87, 185-186. doi:10.1016/S0093-934X(03)00262-1

VanGorp, W., Satz, P., Kiersch, M., \& Henry, R. (1986). Normative data on the Boston Naming Test for a group of normal older adults. Journal of Clinical and Experimental Neuropsychology, 8, 702-705. doi:10.1080/01688638608405189

Waring, S., O’Bryant, S. E., Reisch, J. S., Diaz-Arrastia, R., Knebl, J., \& Doody, R. (2008). The Texas Alzheimer's Research Consortium longitudinal research cohort: Study design and baseline characteristics. Texas Public Health Journal, 60, 9-13.

Welch, L. W., Doineau, D., Johnson, S., \& King, D. (1996). Educational and gender normative data for the Boston Naming Test in a group of older adults. Brain and Language, 53, 260-266. doi:10.1006/brln.1996.0047

White, R. M., Rivera, C. O., \& Davison, C. B. (2000). Nitric oxide-dependent and independent mechanisms account for gender differences in vasodilation to acetylcholine. Journal of Pharmacology and Experimental Therapeutics, 292, 375-380.

Zec, R. F., Burkett, N. R., Markwell, S. J., \& Larsen, D. L. (2007). Normative data stratified for age, education, and gender on the Boston Naming Test. The Clinical Neuropsychologist, 21, 617-637. doi:10.1080/13854040701339356 